\title{
Dia de visita: acompanhando familiares em uma penitenciária de Mato Grosso
}

\section{Maria das Graças de Mendonça S. Calicchio ${ }^{1}$ Reni A. Barsaglini ${ }^{2}$ Universidade Federal de Mato Grosso}

Resumo: Este ensaio tem a proposta de trazer em texto as impressões, os indícios, as marcas e as afetações no trabalho de campo em uma penitenciária nos dias de visitas de familiares. São seguidos três momentos, não estanques, de um certo ritual da visita ao familiar que abrange: o trajeto das mulheres até a penitenciária; a espera para a visita na área externa da penitenciária; os rituais e procedimentos requisitados para a entrada no espaço interno. Diante do olhar, do ouvir e do interagir com o mundo vivido de familiares de pessoas aprisionadas, deixei-me afetar e vi-me possibilitada a descrever detalhadamente os objetos, as situações, a realidade partilhada nos dias de visitações.

Palavras-chave: dias de visita; penitenciária; familiares; mulheres.

${ }^{1}$ Possui graduação em Enfermagem pela Faculdade Estadual de Educação Ciências e Letras de Paranavaí-PR (1995), mestrado em Educação pela UFMT (2015), doutorado em Saúde Coletiva pela UFMT (2019). Enfermeira da Secretaria Municipal de Saúde do município de Sinop (MT), lotada no Centro de Referência à Saúde da Mulher.

2 Possui graduação em Pedagogia pela Universidade Estadual Paulista Júlio de Mesquita Filho (1992), mestrado em Saúde e Ambiente pela UFMT (1999), doutorado em Saúde Coletiva pela Universidade Estadual de Campinas (2006) e pósdoutorado no Centro de Estudos Sociais da Universidade de Coimbra/Portugal (2018). 


\title{
Visiting day: accompanying families on a penitentiary in Mato Grosso
}

\begin{abstract}
This essay has the purpose of bringing in text the impressions, the signs, the marks and the affects in the field work in a penitentiary in the days of family visits. A certain ritual of visiting the family member follows three, non-watertight, moments: women's journey to the penitentiary; waiting for the visit in the external area of the penitentiary; the rituals and procedures required for entry into the inner space. In the face of looking, hearing and interacting with the lived world of relatives of imprisoned people, I am affected; I am able to describe in detail the objects, the situations, the reality shared on visitation days.
\end{abstract}

Keywords: days of visit; penitentiary; relatives; women.

\section{Día de visita: acompañando familiares en una cárcel de Mato Grosso}

Resumen: Este ensayo tiene la propuesta de traer en texto las impresiones, los indicios, las marcas y las afectaciones en el trabajo de campo en una cárcel en los días de visita de familiares. Son seguidos tres momentos, no estancos, de un cierto ritual de visita al familiar que abarca: el trayecto de las mujeres hasta la cárcel: la espera para la visita en el área externa de la cárcel; los rituales y procedimientos solicitados para la entrada en el espacio interno. Delante de la mirada, del oír, y del interactuar con el mundo vivido de familiares de personas aprisionadas, me dejo afectar, me veo posibilitada a describir detalladamente los objetos, las situaciones, la realidad compartida en los días de visitaciones.

Palabras clave: días de visita; cárcel; familiares; mujeres. 
$\mathrm{E}$ leger uma penitenciária como trabalho de campo em uma pesquisa não é tarefa fácil, implicando "que o pesquisador tem que se mover num campo complexo de balizamentos" (SALLA, 2013: 13). Cenário esse que vai além das regras e normas objetivas e produz subjetividades entre pessoas que vivenciam realidades intramuros e extramuros, como aquelas privadas de liberdade e seus familiares.

O aprisionamento de uma pessoa pode tornar seus familiares alvos do processo de criminalização sujeitando-os ao controle social pela prisão e, consequentemente, sofrendo com as medidas coercitivas, mediadas pelo dispositivo de poder, da vigilância e da violência institucional (FOUCAULT, 2013). Por outro lado, a privação de liberdade promove a (re)estruturação de uma rede ampliada dentro e no entorno da instituição prisão, como a movimentação de ambulantes assim como, também, promove a solidariedade entre familiares, amigos e vizinhos (GODOI, 2015). Além disso, a depender do delito (violência doméstica, sexual, por exemplo), pode significar proteção e possibilidade de maior gestão financeira pelo cônjuge (geralmente, quando o preso é o companheiro).

Embora haja a presença de homens, a maior parte da população visitante é composta por mulheres. São elas que exercem os papéis de (re)conectarem a pessoa privada de liberdade (PPL) à realidade fora dos muros da prisão, tornandose as principais mediadoras desse universo, contribuindo ativamente na construção da realidade dentro e fora das celas (GODOI, 2015). Como demostra Dráuzio Varella (2017: 27), "chova, faça frio ou calor, quem passa na frente de um presídio masculino nos fins de semana fica surpreso com o tamanho das filas, formadas basicamente por mulheres". Realidade pouco encontrada no aprisionamento feminino pois, comumente, as mulheres são abandonadas por seus familiares e companheiros (LERMEN e SILVA, 2018).

Ao longo do cumprimento da pena em regime fechado um elemento, reconhecidamente, importante é a visita, cujos significados variam conforme de onde se fala: familiares, PPL, agentes prisionais, defensores, dirigentes etc. Além de permitir a conexão do mundo interno e externo aos muros prisionais, a visita com suas diversas mediações, humanas ou não, potencializa a família à manutenção imaterial e material do privado de liberdade e ao estreitamento dos laços familiares, entretanto, tende a ser prática dispendiosa, deslocando tempo e gastos financeiros às famílias. Ainda assim, colabora para ampliação de solidariedades, sociabilidades, conflitos e, também, possibilita/oportuniza o comércio legal e/ou ilegal (GODOI, 2015).

Diante do exposto, a presente discussão propõe trazer em texto as impressões, os indícios, as marcas e as afetações no trabalho de campo em uma penitenciária nos dias de visitas, conduzido por meu interesse de estar entre os nativos (familiares de PPL), no âmbito interno e externo de uma penitenciária, nos dias de visitas. Ocupar o lugar com os nativos em uma penitenciária foi a maneira que encontrei para me aproximar da experiência de mulheres com algum grau de parentesco com pessoas privadas de liberdade e assim compreender melhor seus pontos de vista. Indo além de somente entrevistar, observar, deduzir e escrever no diário, minha motivação foi a de me inserir, tanto quanto possível, no mesmo 
lugar (físico, social, simbólico) que aquelas pessoas em frente e na antessala de uma penitenciária.

Nas palavras de Márcio Goldman (2005: 159) "quando se está em um tal lugar, é-se bombardeado por intensidades especificas" chamadas de afetos. E ser afetado implica em deixar-se alcançar por uma apreensão de mundo diferente do pesquisador, é olhar o mundo a partir do ponto vista do pesquisado. Simultaneamente, foram realizadas a imersão no campo e a movimentação da escrita, em rearranjos importantes para recriar uma parte dos efeitos do trabalho de campo (LIMA, 2013).

Diante disso, o presente artigo decorre do trabalho de campo de uma pesquisa qualitativa em saúde, compondo o corpus de análise de uma tese de doutorado em Saúde Coletiva, cujo intuito foi de analisar a experiência de mulheres com familiares aprisionados em uma penitenciária masculina de regime fechado do Sistema Prisional de Mato Grosso, localizada no interior do estado (CALICCHIO, 2019).

A penitenciária em questão, que faz parte do Sistema Prisional, é gerida pela Secretaria de Estado de Justiça e Direitos Humanos de Mato Grosso (SEJUDHMT) e está destinada à detenção de homens condenados e homens que aguardam julgamento na região norte do estado. Segundo dados locais, a instituição prisional foi inaugurada em 2006, com capacidade para trezentos e vinte e seis (326) privados de liberdade, sendo que no momento da pesquisa abrigava novecentos e cinquenta e quatro (954) PPL. Para Victor Martins Pimenta (2018), o Estado tende a repreender de forma mais intensa os crimes que envolvem jovens, pobres e de periferia, respondendo pelos crimes mais incidentes no País, como o roubo e o tráfico de drogas.

Conforme dados locais, nessa penitenciária, as PPL são distribuídas em três setores, a saber: a) setor 1: duas alas destinadas para aqueles que exercem trabalhos internos e externos ${ }^{3}$ e uma grande ala chamada de raio (conjunto de celas) nomeado por cores, sendo este Vermelho; b) setor 2: constituído por dois raios nomeados de Laranja e Azul, chamados de raios do convívio; c) setor 3, também constituído de dois raios, nomeados de Amarelo e Verde, caracterizados como raios da igreja por seguirem uma doutrina religiosa. A distribuição espacial dos raios $^{4}$, conforme Jacqueline Sinhoretto et al. (2013), compõe as estratégias forjadas pela comunidade prisional (aprisionados e gestores) para evitar conflitos e facilitar as negociações das regras, sobretudo de convivência social (não estabelecidas oficialmente), pois a diversidade arquitetônica exerce influência direta no convívio entre os aprisionados e desses com a administração.

Nesse cenário, o trabalho de campo foi realizado no segundo semestre de 2018, especificamente, a partir de 15 de julho (total de doze incursões aos finais de semana), intercalando entre os sábados e os domingos. Tais incursões foram entendidas em três momentos não estanques de um certo ritual da visita ao familiar que abrangeu: o trajeto das mulheres até a penitenciária, compartilhando do transporte coletivo durante dois finais de semanas seguidos; a espera para a visita na área externa da penitenciária; e os rituais e procedimentos requisitados para a entrada no espaço interno.

\footnotetext{
3 O trabalho interno refere-se aos serviços de lavanderia, refeitório e limpeza da penitenciária. E o externo está voltado para as atividades fora da penitenciária, no perímetro urbano da cidade.

4 Conforme dados da administração local, nos raios laranja e azul estão presentes membros de uma mesma organização criminosa. No raio verde, além da doutrina religiosa, algumas celas estão reservadas para as PPL de crimes de grande comoção social. No raio vermelho, uma cela abriga a população LGBT (Lésbicas, Gays, Bissexuais, Travestis, Transexuais e Transgêneros).
} 
Diante do olhar, do ouvir e do interagir com o mundo vivido por familiares de pessoas aprisionadas, me vi na possibilidade de descrever detalhadamente os objetos e as situações daquela realidade partilhada. Assim, tão logo eu retornava do campo, relatava em áudio a vivência do dia, evitando a falha de memória e, posteriormente, procurava descrever os fatos marcantes, as reflexões e as autoanálises pertinentes que eram registrados em diário de campo.

Entretanto, com a frequência das visitas e o amadurecimento com o campo, percebi que os itens como a caneta e o caderno, em meio à abundância de sacolas transparentes (trazidas por familiares), faziam-me um ser diferente, permeado por olhares desconfiados, mesmo procurando não escrever na presença das interlocutoras.

A partir do momento em que tais instrumentos foram deixados de lado, levando apenas algumas folhas e uma caneta, ambos acomodados no bolso da roupa, a primeira barreira foi ultrapassada, a minha presença incomodava menos, fui aos poucos aceita, sendo mais uma pessoa, dentre tantas, interagindo entre elas, trocando ideias, procurando valorizar o conhecimento mútuo. Concordo com Alba Zaluar (1985: 20) que, no trabalho de campo, "vivemos uma relação social em que ambas as partes aprendem a se conhecer". Assim, foi possível aproximar-me da realidade de aprisionamento familiar vivenciada no dia de visita, possibilitando trazer o que mais me marcou e afetou durante o trabalho de campo.

Para fins de apresentação, este trabalho foi organizado nas duas partes seguintes. Embora o texto que apresento decorra da própria experiência em campo, o projeto mais amplo do qual deriva (CALICCHIO, 2019) foi submetido e aprovado pelo Comitê de Ética da Universidade Federal de Mato Grosso, Campus de Sinop, sob o Número 2.541.865, de 13/03/2018.

\section{Compartilhando o trajeto das mulheres para a visita}

O ponto de partida para mulheres que desejam visitar seus parentes na penitenciária começa durante a semana com as compras diversas, principalmente as alimentares, e os preparativos corporais como o cuidado com os cabelos e unhas. Mas é no dia da visita, logo nas primeiras horas, que os familiares de PPL iniciam o ritual de ida à penitenciária, em sua maioria se deslocando de suas residências ao terminal do ônibus coletivo. Esse meio de transporte coletivo é gerido pela administração municipal e faz parte do cotidiano de muitas pessoas que se deslocam no perímetro urbano. Nos finais de semana destina-se à zona rural onde se localiza a penitenciária em questão. Saindo do centro da cidade às seis horas da manhã, percorre a média de $12 \mathrm{~km}$, por cerca de uma hora, entre bairros centrais e periféricos sendo $5,5 \mathrm{~km}$ na zona rural. É uma linha não exclusiva, de modo que outras pessoas que não necessariamente se destinam à penitenciária podem usufruir desse transporte, embora não tenha observado nenhuma delas embarcando ou desembarcando que não fosse visitante da penitenciária local5.

Diante da expressão clássica de Bronislaw Malinowski (1978), “os imponderáveis da vida real", o meu anseio foi de observar, nas situações, os cenários e os contextos em suas plenas realidades. Para isso aventurei-me a ser passageira de um ônibus que carrega mulheres para a visitação em uma penitenciária. A estratégia de acompanhar os nativos em seus trajetos habituais, como propõe José

\footnotetext{
5 Nesse ônibus consta um letreiro escrito Presídio. Essa identificação nos finais de semana parece mobilizar repulsa da população que depende do transporte coletivo. Pode-se dizer tratar-se de uma marca que informa sobre a identidade envolvida, como na acepção de estigma de Goffman (2015).
} 
Guilherme Cantor Magnani (2002), possibilitou revelar um mapa de deslocamentos pontuado por significados materiais e imateriais/simbólicos.

Assim, com olhos e ouvidos atentos, ao chegar no terminal do transporte coletivo, fiquei observando os gestos, as expressões verbais e não verbais das passageiras que adentravam no terminal dos ônibus de bicicletas e motos, oriundas de seus bairros, deixando os veículos no estacionamento desse espaço público. A maioria formada por mulheres (sejam jovens, adultas e idosas) sempre acompanhadas por crianças e apresentando as mesmas características - carregadas de sacolas transparentes, recheadas de potes coloridos, sortidas de alimentos e comida -, o que é chamado de "jumbo"6. Ali, o ritual de interações e sociabilidades já se iniciava. Tal como apontado José Alcântara Júnior (2010), o ônibus como um ambiente social e temporário favorece as interações sociais entre as pessoas e produz pequenas formas sociais, fluídas no interior desse veículo.

Nessa perspectiva, recorremos à categoria pedaço trazida por Magnani (2002; 2009) para demonstrar que um transporte coletivo pode ser considerado espaço intermediário entre o privado (a casa) e o público. Uma referência espacial, em que a presença regular das pessoas, juntamente a um código de reconhecimento e comunicação entre elas, possibilita distinguir determinados membros como pertencentes ao mesmo grupo de relações sociais (MAGNANI, 2002). Porém, não basta frequentar o espaço para serem pessoas do pedaço, é preciso pertencer a uma rede de relações de procedência, de parentescos, de vizinhança, (de visitantes de uma unidade penitenciária, podemos dizer), e ser capaz de perceber de forma clara e imediata quem são as do pedaço, em uma experiência concreta e compartilhada (MAGNANI, 2009).

Já embarcada, procurava um lugar no fundo para facilitar as observações e as interações, ao mesmo tempo em que fazia parte delas; como assinala Cristina Larrea Killinger (2017), no trabalho de campo, nativos e pesquisadores fazem parte da mesma dinâmica cotidiana. Com olhos bem atentos e disposta a uma escuta sensível, observava as expressões corporais e as falas. E não demorava muito para que eu pudesse fazer os primeiros contatos verbais com algumas passageiras sob o acolhimento de olhares desconfiados. Diante desse palco circulante, procurava respeitar e compreender suas realidades sociais, pois "o que os nativos pensam, fazem e sentem afeta o nosso olhar sobre eles e a nossa compreensão do mundo" (KILLINGER, 2017: 192).

Durante todo o trajeto as passageiras permaneciam sentadas havendo, naqueles dias, espaço suficiente para todas. Uma parte delas se acomodava no fundo do ônibus, principalmente as aparentemente mais jovens, com suas crianças, suas sacolas e muita disposição para colocar a conversa em dia, juntando-se aos poucos com aquelas que iam embarcando nas paradas do itinerário do ônibus. Outras mulheres permaneciam nos seus bancos, um pouco mais distantes daquele grupo de mulheres mais falantes, conversando em tom baixo de voz, enquanto outras permaneciam em silêncio.

No sentido proposto por Suely Maciel (2014), a conversa é uma forma de comunicação, podendo ser entendida como trocas enunciativas que envolve entre os interlocutores a produção e a recepção de mensagens dentro de um fluxo contínuo de afirmações, contraposições, diferenças e proximidades. Claude LéviStrauss (1975: 68) nos lembra que na fala "não temos consciência dos fonemas que utilizamos para diferenciar o sentido de nossas palavras”. Dessa forma, a

${ }^{6}$ Jumbo é uma expressão nativa usada para denominar as sacolas transparentes (contendo comida, alimentos e outros pertences) que as mulheres levam para seus parentes aprisionados. Na penitenciária local, o jumbo do tipo cobertores, ventiladores e roupas, são entregues fora da visita social, nas quartas-feiras. 
conversa como meio de diálogo se materializa na linguagem como a realidade de qualquer forma de comunicação.

Mantendo a escuta sensível e atentando-me à história contada pela companheira de banco e visitante da penitenciária, que aparentava cerca de 40 anos, percorri o caminho. Ela foi relatando que se encontrava desempregada, que recentemente recebeu a sogra em sua casa com deficiência visual onde residem dois filhos menores de idade do companheiro privado de liberdade, agregando-se a mais três filhos da parte dela (o filho menor era com o atual companheiro, uma filha de cinco anos e outra de dez anos de um antigo relacionamento amoroso). Desse modo, a unidade doméstica dessa passageira é composta de seis membros (cinco menores de idade e uma idosa). A respeito da unidade doméstica, Paula Orchiucci Miura et al. (2018) consideram-na como espaço de convivência entre as pessoas, tendo ou não vínculo familiar, ou por eventualidade, como o caso de abrigar alguém na residência.

Na maioria das vezes, nesse tipo de unidade, os membros estão ligados por laços de solidariedade e sobrevivência (SARTI, 2004). No caso do aprisionamento de um pai/mãe, existe a possibilidade de as pessoas viverem juntas por uma questão de sobrevivência/conveniência, visto que a ausência de um ou de ambos, ou da impossibilidade de manter os cuidados com os filhos, resulta no acolhimento provisório em casa de abrigo, orfanato ou residência de familiares (parentes próximos ou por determinação da Justiça) (SILVA, 2015).

Na companhia da passageira, ficava observando que o ônibus fazia o percurso em meio à movimentação de outros veículos, comércios, casas, até adentrar a estrada rural de chão/terra batida, marcada por uma invasão de nuvens de poeira, embaçando a visão dos presentes. Além do ar nevoento pela poeira, o que turvava a visão, o olfato também era castigado devido à presença de um curtume cujo odor insistiu em nos acompanhar boa parte do percurso final (cerca de 20 minutos na estrada rural). Não obstante, a sensibilidade ao odor desagradável não era homogênea entre as passageiras, principalmente entre as veteranas desse percurso. Sabe-se que as sensibilidades sensoriais variam entre as pessoas por manter articulação com os saberes predominantes no tempo/espaço/ambiente. A existência de certa limitação física e simbólica, seus respectivos odores deveriam se restringir a determinados elementos/objetos/situações/contexto, porém os cheiros podem gerar repulsa e sensação de desordem quando extrapolam fronteiras (e isto reflete em perigo), quando surgem onde não deveriam, como bem tratou Alain Corbin (1987). No caso, adentrava invadindo local onde havia cheiros de corpos lavados, perfumados, comidas etc. Depois de sessenta minutos, davase por encerrado o trajeto (urbano - rural) e ali desembarcamos, cada uma levando consigo seus pertences, suas alegrias, suas tristezas. A partir daqui, seguiam-se as interações, dessa vez, na área externa da penitenciária.

\section{A visita de familiares: a interface externa na penitenciária}

As observações na área externa da penitenciária me possibilitaram aproximar da realidade imposta pelo aprisionamento no dia da visita, como o fluxo de visitantes, as movimentações de chegada e saída de veículos (viaturas, carros, táxis, motos), o seu entorno, o serviço ambulante, as interações entre os familiares, as sociabilidades, o estreitamento dos laços de amizade, solidariedades e apoio, conflitos, dentre outras questões marcantes a mim e trazidas nessa apresentação. 
O espaço físico externo da penitenciária, nativamente chamado pelas visitantes de a "porta do Ferrugem", era extenso, embora uma pequena parte se destinava ao acolhimento das visitantes. Esse espaço era coberto e muito pequeno pela quantidade de visitantes, circundado por bancos de cimentos insuficientes para o dia das visitas e, possivelmente, desconfortável em dias chuvosos. Observei a existência de várias e minúsculas janelas com grades, representando cada raio, cuja função era de facilitar a distribuição das senhas para a entrada ao espaço interno da penitenciária. Nas paredes com pinturas antigas, havia vários lembretes visando à colaboração da comunicação entre a penitenciária e os visitantes, dentre os quais constava o cronograma mensal das visitas. Havia também dois banheiros com chuveiros, bancadas para a troca de fraldas e, do lado de fora, uma torneira para uso das visitantes.

Dividindo o espaço externo funcionava pequeno comércio local (serviço ambulante) a alguns metros do portão principal da penitenciária. Esse serviço era organizado por um senhor e tratava-se de um ponto comercial de apoio utilizado pelas visitantes para guardarem seus pertences, como os capacetes, as bolsas, os celulares, mas também oferecia aluguel de chinelos, de roupas, sendo cobrada taxa que variava entre $\mathrm{R} \$ 5$ a $\mathrm{R} \$ 10$. Em contrapartida, o ambulante oferecia gratuitamente uma balança para as visitantes que estavam na dúvida em relação ao peso dos alimentos e da comida trazidos de casa, que não deveriam ultrapassar de três quilos por família.

Segundo Roberto DaMatta (1986: 36), "nem tudo que é alimento é comida. Alimento é tudo aquilo que pode ser ingerido para manter uma pessoa viva, comida é tudo que se come com prazer, de acordo com as regras mais sagradas de comunhão". A comida, conforme esse mesmo autor, vai além de nossas individualidades, define nossas identidades sociais e culturais. Quando a comida adentrava na penitenciária, trazida por um familiar, traduzia subjetividades, demonstrava zelo e afeição (DUARTE, 2013) e, "as mulheres claramente enxergam a comida durante as visitas como ocasiões para recriar ou importar a 'casa' para dentro das paredes da prisão" (COMFORT, 2007: 107).

Logo quando chegava à área externa, percebia grande movimentação de táxis. Eram visitantes oriundas de cidades da região próxima à penitenciária e até de outro estado, algo que me chamou atenção, pois repercutia nas despesas financeiras e no cansaço físico, conforme relataram algumas mulheres. Por outro lado, movimentava a rede de taxistas da cidade e região.

\begin{abstract}
As visitantes me disseram que pagam um táxi para vir da cidade de origem à penitenciária em Sinop, percorrendo quatro horas de viagem e trazendo, também, os filhos pequenos (...). Duas delas me relataram que residem no sul do Pará, saem um dia antes de casa, ao chegarem na rodoviária pegam um táxi em direção à penitenciária. (Nota de campo, 09/08/2018).
\end{abstract}

Com a chegada do ônibus coletivo trazendo as familiares, foi possível observar a dimensão do número de pessoas presentes no dia da visita e suas características. As mulheres se diversificavam em grupos etários (jovens, jovens-adultas, idosas), conforme o dia de visitação. As visitas seguiam um cronograma (mensal, anexado na parede externa, próximo ao local de distribuição de senha) em que as senhas eram distribuídas conforme as celas dos respectivos raios (amarelo $e$ verde; vermelho, azul e laranja), alternando entre sábados e domingos. Nos dias de visitas dos raios do convívio (vermelho, azul e laranja), existia a presença de maior quantidade de mulheres aparentemente jovens, inclusive várias delas grávidas, enquanto as visitantes dos raios da igreja (amarelo e verde) se dividiam entre as aparentes jovens-adultas e idosas. 
Entre o público visitante chamava a atenção o expressivo número de crianças. Elas se misturavam com as visitantes e interagiam com outras crianças. Brincavam com o que encontram: lixo, pedriscos, garrafas pets, dentre outros. Entretanto, os momentos de diversão eram intercalados com choros, ora porque haviam se desentendido entre elas; ora porque as mães, extremamente irritadas, chamavam-lhes atenção, sem se intimidarem com as demais pessoas ao redor. Como bem retrata Andréa Marília Vieira Santos (2006), a rotina imposta no dia da visita, a falta de espaço adequado para recebê-las e o tratamento dispensado pelos agentes prisionais repercutem em uma série de desgastes físico-emocionais, manifestados pela ansiedade, choro e euforia.

$\mathrm{Na}$ "porta do Ferrugem" observava a presença de poucos homens, alguns deles eram líderes religiosos que assim chegavam em pequenos grupos ou duplas, improvisavam de forma rápida a leitura da Bíblia e minutos depois adentravam à penitenciária. A religiosidade nas penitenciárias, a priori, visa colaborar na redução dos impactos da privação de liberdade e preparar para o retorno do egresso (LIVRAMENTO e ROSA, 2016).

No instante em que as visitantes (as que já se encontravam na penitenciária) percebiam a chegada do transporte coletivo, entre elas, havia grande rebuliço motivado pela fila de distribuição das senhas. Essas senhas eram entregues por ordem de chegada e se configuravam em passaportes para que visitantes pudessem adentrar nas dependências internas da penitenciária ao encontro de seus entes. As mulheres tomavam suas posições na fila, aguardando abertura das minúsculas janelas para a entrega das tais senhas.

Nesse ordenamento, as visitantes se cumprimentavam, guardavam os lugares para as colegas, ajudavam a cuidar das crianças e, aos poucos, a fila estava formada. Depois de duas horas (em média) em que as elas haviam chegado nas dependências externas, as senhas eram distribuídas. Concomitante, os agentes prisionais conferiam a data de validade das carteirinhas de identificação da visitante, aproveitando desse momento para listar os privados de liberdade que receberiam a visita do familiar para, posteriormente, serem retirados das respectivas celas e serem levados ao local destinado à visita social.

Após esse procedimento, a fila se desfazia e outras dinâmicas do dia da visita tomavam lugar. As visitantes passavam a se locomover com mais frequência de um canto a outro, se cumprimentavam, conversavam entre si, mostrando-se solidárias umas com as outras. Aos poucos formavam grupos, fumando, em volta de um carro, sentadas na calçada ou tomando um café trazido de casa.

Pode-se pensar que as mulheres nessa sociabilidade grupal se reconheciam, pois transitavam em espaços comuns, compartilhavam as condições objetivas do dentro de uma rede de relações concretizadas no dia da visita. Assim, buscavam um ponto de aglutinação para fortalecerem seus laços, de encontrarem seus iguais, de marcarem suas diferenças (MAGNANI, 2002). Gilberto Velho (2003: 21) pactua da ideia de que o reconhecimento da diferença é elemento constitutivo da sociedade complexa, onde se vive "não só o conflito, mas a troca, a aliança $e$ a interação grupal, constituindo a própria vida social através da experiência, da produção e reconhecimento explícito ou implícito de interesses e valores diferentes".

Para as visitantes a "porta do Ferrugem", coaduna-se com o que diz Magnani (2009: 142), como espaço que "permite encontros e trocas entre elas nas suas diferenças, seja de classe social, escolaridade, origem, local de moradia e vizinhança: é como se pudessem apreciar, para além da condição comum que as 
une, as diferenças entre si”. Assim, nas interações tem lugar, também, as divergências e conflitos.

Percebo que as mulheres mesmo sendo tão diferentes, em termos aparentes de idade, vestimentas e localidades, à medida que se aproximam, se cumprimentam, e uma vai perguntando a outra como foi a semana, ali, surgem vários assuntos (...). Uma delas me contou que havia tomado as "dores "da amiga que havia sido traída pelo marido aprisionado por uma mulher (a talarica7) desconhecida entre elas nos dias de visita. (Nota de campo, 09/07/2018)

Em duplas, sozinhas, com ou sem crianças, era comum as visitantes se deslocarem com frequência para as proximidades do banheiro que ficava um pouco afastado do tumulto. Observava, principalmente entre as mais jovens que, ao chegarem no espaço externo, apresentavam-se com determinada roupa, procuravam o banheiro e, minutos depois, apareciam transformadas, caprichadas nas roupas, nos calçados, na maquiagem e no perfume. Concordando com David Le Breton (2007), a maneira de se vestir, de se pentear e ajeitar o rosto, de cuidar do corpo, responde a uma ação cotidiana de se apresentar socialmente e de se representar e, conforme as circunstâncias, impõe um estilo de presença, que integra a identidade feminina. Como destacam Christiane Moura Nascimento e Luiz Carlos Avelino da Silva (2014) o embelezamento assim como todos os cuidados corporais fazem parte da mulher ocidental, produto da realidade e da relação do corpo em determinada cultura e tempo.

Desse modo, o banheiro externo da penitenciária, para além dos cuidados pessoais, no dia da visita tornava-se também o espaço de diversas interações dos mais variados tipos e funções. Portanto, o banheiro como pedaço é uma referência espacial, lugar de passagem, de comunicação e interação (MAGNANI, 2002). Como espaço reservado, o banheiro escapava um tanto às vigilâncias dos agentes prisionais, portanto, facilitava as trocas de informações oportunizando o tráfico de drogas, a receptação e ocultação de objetos ilícitos (nos próprios corpos, por exemplo).

Hoje, uma das mulheres relatou-me que, nas proximidades do banheiro, é preciso ter muito cuidado, "ser cega, surda e muda", pois há mulheres que estão ali para colaborar com os maridos na superação da privação de liberdade. Mas, há outras, que vão à penitenciária para ganhar a vida no tráfico de drogas. (Nota de campo, 28/07/2018)

Ao lado, na parte externa do banheiro, havia uma torneira, muito frequentada pelas visitantes que necessitavam manter a higienização, principalmente dos pés, pois grande parte delas eram oriundas de bairros periféricos, sem asfalto (agravado por se tratar de uma época de muita poeira) e elas faziam questão do asseio. Essa origem periférica retrata o perfil seleto do Sistema Prisional Brasileiro, sendo a maioria formada por jovens, negros, pobres, de baixa escolaridade e moradores de periferia (PIMENTA, 2018).

Após esse momento externo, a porta da penitenciária se abria e as visitantes adentravam, uma dupla de cada vez, a outro espaço intermediário em que tomavam lugar outros tantos procedimentos do ritual da visita, sendo o local onde era realizada a revista e que abordo no tópico seguinte.

7 As talaricas são mulheres que ocasionalmente estão nas penitenciárias para relacionar-se amorosamente com um privado de liberdade. Essas mulheres não são aceitas entre as demais visitantes, são consideradas um risco iminente para outras mulheres de PPL pela possibilidade de se envolverem com os seus companheiros (LIMA, 2013). 


\section{A interface interna da penitenciária: procedimentos e rituais}

No espaço interno da penitenciária designado de hall de entrada, interagem humanos e não humanos em procedimentos que são decisivos para se concretizar a visita ao familiar propriamente. São rituais de averiguações que incidem sobre as pessoas/visitantes (documentos, corpo) e sobre coisas (alimentos, outros produtos e objetos) que se pretende carregar para dentro e visam identificar situações irregulares impedindo a entrada do que não é permitido (geralmente, armas, munições, drogas, celulares) ou em quantidade fora das normas.

O conjunto de rituais, concordando com Mariza Peirano (2006: 9), é "constituído de sequências ordenadas e padronizadas de palavras e atos, em geral expressos por múltiplos meios" que se conformam em um sistema cultural de comunicação simbólica. Como conclui essa autora, é um evento especial, estereotipado e peculiar, transmite valores e conhecimentos, visões de mundo dominantes e conflitantes, revelando o que é comum em determinado grupo. Nos rituais de entrada à penitenciária, primeiramente eram chamados os familiares de PPL que trabalhavam internamente no ambiente prisional e após, as mulheres que aguardavam para a visita íntima e assim sucessivamente. Ao adentrar no hall de entrada as visitantes se deparavam com uma sala espaçosa e vários equipamentos, entre eles: uma balança, um scanner, um portal detector de metais (semelhantes aqueles encontrados em agências bancárias). Esses dois últimos aparelhos faziam parte da revista mecânica ${ }^{8}$ cuja finalidade era de identificar objetos proibidos e ilícitos.

Dessa forma, novos rituais tomavam lugar para que a passagem se efetivasse. No primeiro momento, eram pesados os alimentos e a comida (limite de três quilos visitante) e na sequência levados pelas visitantes ao scanner, objetivando averiguar a presença de materiais ilícitos (metais e drogas), identificados por meio de cores. No terceiro momento, as visitantes se direcionavam para um balcão, onde se realizava a leitura do código de barras nas carteiras de identificação individual com o propósito de identificar familiares com possíveis problemas com a Justiça ou que, por algum motivo, encontravam-se impedidos de visitar seu parente, dentre os quais: pendências de documentos ou pedido da própria PPL (MATO GROSSO, 2014). Sequencialmente, as visitantes se dirigiam ao portal detector de metais, cuja finalidade era detectar a presença de celulares e /ou armas.

No momento em que observava a passagem de visitantes pelo portal detector de metais, testemunhei duas intercorrências: o equipamento acusou a presença de algo suspeito em uma senhora que possuía um tipo de metal nos dentes. Ela teve que ser revistada, inclusive sua boca. Outra portava metal em uma das pernas, possivelmente uma "prótese", e apresentou uma declaração médica aos agentes prisionais. Uma vez passadas pelo portal detector de metais, as visitantes ficavam no saguão do hall de entrada, em filas, em silêncio total, cabisbaixas (nenhuma troca de olhar, tampouco conversa entre elas) aguardando para passarem em um equipamento chamado de banqueta (espécie de assento), usado para identificar objetos metálicos introduzidos na parte íntima da mulher como, por exemplo, celulares. Com a permanência somente da visitante e da agente prisional, a sala desse tipo de revista era pequena e as mulheres sentavam na banqueta a uma

\footnotetext{
${ }^{8}$ Assim como a revista mecânica, outras modalidades de revista nas penitenciárias de Mato Grosso estão previstas conforme o POP (Procedimento Operacional Padrão do Sistema Penitenciário), a saber: pessoal (por ordem verbal: averíguam-se partes do corpo e vestes), manual (inspeção das vestes), veículos (verificado todo veículo que adentrar ou sair da unidade prisional) (MATO GROSSO, 2014).
} 
certa distância da agente prisional. Caso houvesse suspeita de presença de itens proibidos, as visitantes eram direcionadas à Unidade de Pronto Atendimento do município para exames de imagem (raio-x) mas, para isso, precisavam concordar com tal procedimento, caso contrário ficava proibida a visitação9 .

No hall de entrada, circulavam e interagiam pretensas visitantes, agentes prisionais e aparatos tecnológicos demonstrando toda a dureza do local. Tais artefatos pareciam carregar maior precisão, complementando outras modalidades da revista anteriormente destacadas, com objetividade e agilidade na inspeção, como também menos exposição dos familiares ao procedimento, sendo inclusive a principal justificativa central do uso desses equipamentos.

Uma vez finalizada a revista, as visitantes estavam aparentemente preparadas para o encontro com seus entes, recolhendo suas sacolas e permanecendo em um espaço aberto, em silêncio, no aguardo dos demais familiares, sob os olhares vigilantes da equipe de agentes prisionais. Após alguns minutos de espera (média de 15 minutos), elas eram liberadas para percorrerem uma área aberta, próxima ao pavilhão administrativo, até chegarem aos respectivos raios. Cada conjunto de raios comportava um espaço físico para os encontros familiares, chamados de "ponto de encontro". Aparentavam ser bem conservados, com paredes pintadas, mesas, bancos de cimento e banheiros recém-construídos. A estrutura desse local era recém-reformada, em decorrência da destruição de sua estrutura física durante a última rebelião, em 2017, que resultou em cinco mortos e 27 feridos, como destacado na ocasião: "na manhã desta terça-feira (11.04.2017) na Penitenciária (...) presos ocuparam os raios Laranja e Amarelo da unidade prisional" (MATO GROSSO, 2017).

No "ponto de encontro", familiares e PPL tinham duas horas para se (re) encontrarem, momento em meio ao coletivo em que forjavam as suas privacidades valendo-se de pequenos lençóis estendidos no piso. Assim, organizavam os alimentos, a comida, as mamadeiras e as fraldas. Outras visitantes e seus entes permaneciam sentados e circundados em bancos de cimentos, dividindo os alimentos e a comida trazida de casa.

De volta ao espaço externo, percebia "certa" quantidade de produtos devolvidos durante o procedimento de inspeção das visitantes, tais como produtos de higiene pessoal, pois, não eram permitidos aos familiares trazerem de casa.

\section{Algumas considerações finais}

O trabalho de campo nos dias de visitas de familiares em uma penitenciária levou-me a estar lá com os nativos. Essa proximidade e sensações do momento oportunizaram-me percepções e pensamentos estando no mesmo local de quem, de fato, vivencia a privação de liberdade de um ente, como as mães e as companheiras, além de proporcionar a aproximação da experiência do aprisionamento de familiar, deixando-me marcas e afetações.

Nesse cenário, deixei-me afetar não somente pela apreensão cognitiva dos afetos, mas buscando alcançar e compreender entre as visitantes de uma penitenciária, diferentes formas de vivenciar o aprisionamento do familiar no dia da visita. A priori, as afetações surgiram como passageira de um transporte coletivo, após, como visitante na área externa da penitenciária e, na sequência, no espaço interno de escrutínio da instituição prisional. Nessa perspectiva, o intuito não era

9 Nas unidades prisionais de Mato Grosso, a Instrução Normativa n. ${ }^{0}$ oo2/GAB/SEJUDH, de 16 de julho de 2014, proíbe a revista íntima, chamada de revista vexatória, que são procedimentos que envolvem averiguações nos órgãos genitais femininos dentro das unidades penitenciárias. 
apenas observar e coletar informações, mas também valorizar as relações sociais e o conhecimento mútuo entre as visitantes.

Por fim, ocupar o lugar de visitante em uma penitenciária possibilitou alargar o universo da pesquisa, pois estar entre os nativos corroborou a compreensão dos significados e elementos da prática da visita empreendida pelas mulheres diante do aprisionamento de um familiar. Diante das palavras ditas e não ditas, das interações no campo e sob o prisma de quem esteve lá em situações concretas, deixei-me afetar pelo aprisionamento de familiar e os esforços para o contato.

Espero que afetações deste trabalho de campo, trazidas em texto estando $a q u i$, possam contribuir para visibilizar e sensibilizar sobre a experiência dessas mulheres e as facetas das repercussões do aprisionamento no dia de visita que as alcançam mais fortemente, colaborando para a elaboração de planos e ações dirigidas a elas e ao familiar privado de liberdade como direito social.

Recebido em 28 de outubro de 2019.

Aceito em 10 de novembro de 2019.

\section{Referências}

ALCÂNTARA Jr., José. Sociabilidades em ônibus urbano. São Luís: EDUFMA, 2010.

CALICCHIO, Maria das Graças de M. S. Além das Celas: experiência de mulheres com familiar em cumprimento de pena em regime fechado, Mato Grosso. Tese (Doutorado em Saúde Coletiva) - Programa de Pós-Graduação em Saúde Coletiva. Universidade Federal de Mato Grosso, Cuiabá, 2019.

COMFORT, Megan. Partilhamos tudo o que podemos: a dualização do corpo recluso nos romances através das grades. Análise Social, 185 (42): 1055-1079, 2007.

CORBIN, Alain. Saberes e Odores. São Paulo: Cia. das Letras, 1987.

DAMATTA, Roberto. O que faz o brasil, Brasil? Rio de Janeiro: Rocco, 1986.

DUARTE, Thais Lemos. Amor, Fidelidade e Compaixão: "sucata" para os presos. Revista Sociologia e Antropologia, 3: 621-641, 2013.

FOUCAULT, Michel. Vigiar e Punir. Rio de Janeiro: Editora Vozes, 2013.

GODOI, Rafael. Fluxo em Cadeias: as prisões de São Paulo na virada dos tempos. Tese (Doutorado em Sociologia) - Faculdade de Filosofia, Letras e Ciências Humanas, Departamento de Sociologia, USP, São Paulo, 2015.

GOLDMAN, Márcio. Jeanne Favret-Saada, os afetos, a etnografia. Cadernos de Campo, 13 (13): 149-153, 2005. 
GOFFMAN, Erving. Estigma: notas sobre a manipulação da identidade deteriorada. Tradução: Mathias Lambert. 4. ed. Rio de Janeiro: LTC, [1981] 2015.

KILLINGER, Cristina Larrea. Além da etnografia: olhares sobre o trabalho dos pesquisadores. Salvador: EDUFBA, 2017. pp. 191-202.

LE BRETON, David. A sociologia do corpo. Petrópolis: Vozes, 2007.

LERMEN, Helena Salgueiro; SILVA, Martinho Braga e. Masculinidades no Cárcere: Homens que visitam suas Parceiras Privadas de Liberdade. Psicologia Ciência e Profissão, 38 (núm. esp. 2): 73-87, 2018.

LIMA, Jacqueline Stefanny Ferraz de. Mulher fiel: as famílias das mulheres dos presos relacionados ao primeiro comando da capital. Dissertação (Mestrado em Antropologia Social) - Programa de Pós-Graduação em Antropologia Social, Universidade Federal de São Carlos, São Carlos, 2013.

LÉVI-STRAUSS, Claude. Antropologia estrutural. Rio de Janeiro: Tempo Brasileiro, 1975 .

LIVRAMENTO, André Mota do; ROSA, Edinete Maria. Homens no cárcere: estratégias de vida na prisão. Pesquisas e Práticas Psicossociais, 11 (2): 412-426, 2016.

MACIEL, Suely. "Comunicação radiofônica e interatividade à luz do dialogismo e da interação verbal. In: SIMIS, A. et al. (org.). Comunicação, cultura e linguagem. São Paulo: Editora UNESP, 2014. pp. 79-105.

MAGNANI, José Guilherme Cantor. De perto e de dentro: notas para uma etnografia urbana. Revista Brasileira de Ciências Sociais, 17 (49): 14-29, 2002.

MAGNANI, José Guilherme Cantor. Etnografia como prática e experiência. Horizontes Antropológicos, 32 (15): 129-156, 2009.

MALINOWSKI, Bronisław. Os argonautas do pacífico ocidental: um relato do empreendimento e da aventura dos nativos nos arquipélagos da Nova Guiné. São Paulo: Abril Cultural, 1978.

MATO GROSSO. Notícias. Forças de segurança são acionadas para conter rebelião em presídio em Sinop. Segurança Pública. 11 abr. 2017.

MATO GROSSO. Secretaria de Estado de Justiça e Direitos Humanos. Normas de visitas conforme o POP-Procedimento Operacional Padrão do Sistema Penitenciário de Mato Grosso. Cuiabá: Secretaria Adjunta de Administração Penitenciária, 2014.

MATO GROSSO. Poder Executivo. Decreto $n^{0}$ 103, de 06 de maio 2019. Dispõe sobre a prestação de assistência material referente a produtos permitidos e não fornecidos pelos estabelecimentos penais do Sistema Penitenciário. Diário oficial do Estado. Ano CXXVII, N. 27497, 2019.

MIURA, Paula Orchiucci; SILVA, Ana Caroline dos Santos; PEDROSA, Maria Marques Marinho Perônio; COSTA, Marianne Lemos; FILHO, José Nilson Nobre. Violência Doméstica ou Violência Intrafamiliar: análise dos termos. Psicologia \& Sociedade, 30 (e179670): 1-13, 2018.

NASCIMENTO, Christiane Moura; SILVA, Luiz Carlos Avelino da. Sujeito mulher: a imagem da beleza. Revista Subjetividades, 14 (2): 343-357, 2014. 
PEIRANO, Mariza. Temas ou Teorias? O estatuto das noções de ritual e de performance. Cadernos de Campos, 7 (2): 9-16, 2006.

PIMENTA, Victor Martins. Por Trás das Grades: o encarceramento em massa no Brasil. Rio de Janeiro: Revan, 2018.

RECONDO, Felipe. "Cantinas de presídios financiam o PCC- Em MS, quem não é de facção paga mais; lucro banca melhorias". Brasília, O Estado de S. Paulo, 16 out. 2009. Disponível emhttps://www.estadao.com.br/noticias/geral,cantinasde-presidios-financiam-o pcc,451290. Acesso em 20 de agosto de 2019.

SALLA, Fernando. “A Pesquisa na prisão: Labirintos”. In: LOURENÇO, Luís Claudio; GOMES, Gerder Luiz Rocha (org.). Prisões e Punição no Brasil Contemporâneo. Salvador: EDUFBA, 2013. pp. 11-28.

SANTOS, Andréa Marília Vieira. Pais Encarcerados: Filhos Invisíveis. Revista Psicologia Ciência e Profissão, Brasília, 26 (4): 594-603, 2006.

SARTI, Cíntia. A Família como Ordem Simbólica. Revista de Psicologia da USP, 15 (3): 11-28, 2004.

SINHORETTO, Jacqueline. SILVESTRE, Giane. MELO, Felipe. A. L. de. O encarceramento em massa em São Paulo. Tempo Social, 15 (1): 83-106, 2013.

SILVA, Martinho Braga e. Saúde Penitenciária no Brasil: plano e política. Brasília: Verbena, 2015.

VARELLA, Dráuzio. Prisioneiras. São Paulo: Ed. Companhia das Letras, 2017.

VELHO, Gilberto. Projeto e Metamorfose: Antropologia das Sociedades Complexas. Rio de Janeiro: Jorge Zahar Editor, 2003.

ZALUAR, Alba. A máquina e a revolta: as organizações populares e o significado da pobreza. São Paulo: Brasiliense, 1985. 


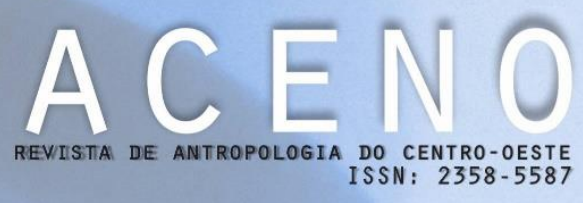

A Aceno - Revista de Antropologia do Centro-Oeste recebe o ano inteiro, em

\section{FLUXO CONTÍNUO, artigos livres, resenhas, ensaios fotográficos, dossiês (propostas).}

Interessados na submissão de trabalhos e também em atuar como

\section{pareceristas}

podem realizar seus cadastros em

https://periodicoscientificos.ufmt.br/ojs/index.php/aceno 